\title{
Simultaneous measurement of temperature and humidity with microstructured polymer optical fiber Bragg gratings
}

Woyessa, Getinet; Pedersen, Jens Kristian Mølgaard; Fasano, Andrea; Nielsen, Kristian; Markos, Christos; Rasmussen, Henrik K.; Bang, Ole

Published in:

25th International Conference on Optical Fiber Sensors

Link to article, DOI:

$10.1117 / 12.2265884$

Publication date:

2017

Document Version

Publisher's PDF, also known as Version of record

Link back to DTU Orbit

Citation (APA):

Woyessa, G., Pedersen, J. K. M., Fasano, A., Nielsen, K., Markos, C., Rasmussen, H. K., \& Bang, O. (2017).

Simultaneous measurement of temperature and humidity with microstructured polymer optical fiber Bragg gratings. In Y. Chung, W. Jin, B. Lee, J. Canning, K. Nakamura, \& L. Yuan (Eds.), 25th International Conference on Optical Fiber Sensors (Vol. 10323). [103234T ] SPIE - International Society for Optical Engineering. https://doi.org/10.1117/12.2265884

\section{General rights}

Copyright and moral rights for the publications made accessible in the public portal are retained by the authors and/or other copyright owners and it is a condition of accessing publications that users recognise and abide by the legal requirements associated with these rights.

- Users may download and print one copy of any publication from the public portal for the purpose of private study or research.

- You may not further distribute the material or use it for any profit-making activity or commercial gain

- You may freely distribute the URL identifying the publication in the public portal 


\title{
Simultaneous measurement of temperature and humidity with microstructured polymer optical fiber Bragg gratings
}

\author{
Getinet Woyessa $^{* 1}$, Jens Kristian Mølgaard Pedersen ${ }^{1}$, Andrea Fasano ${ }^{2}$, Kristian Nielsen ${ }^{1}$, Christos \\ Markos $^{1}$, Henrik Koblitz Rasmussen ${ }^{2}$, Ole Bang ${ }^{1}$ \\ ${ }^{1}$ DTU Fotonik, Department of Photonics Engineering, Technical University of Denmark, DK-2800 \\ Kgs. Lyngby, Denmark; ${ }^{2}$ DTU Mekanik Department of Mechanical Engineering, Technical \\ University of Denmark, DK-2800 Kgs. Lyngby, Denmark
}

\begin{abstract}
A microstructured polymer optical fiber (mPOF) Bragg grating sensor system for the simultaneous measurement of temperature and relative humidity $(\mathrm{RH})$ has been developed and characterized. The sensing head is based on two in-line fiber Bragg gratings recorded in a mPOF. The sensor system has a root mean square deviation of $1.04 \% \mathrm{RH}$ and $0.8{ }^{\circ} \mathrm{C}$ in the range 10 to $90 \% \mathrm{RH}$ and 20 to $80^{\circ} \mathrm{C}$. The proposed sensor system is easy to fabricate, cheap and compact.
\end{abstract}

Keywords: Polymer waveguides, fiber Bragg gratings, fiber optics sensors, humidity, temperature

\section{INTRODUCTION}

The interest in polymer optical fiber (POF) sensors is steadily increasing because of their low processing temperature, high flexibility in bending, high fracture toughness, ease of handling and non-brittle nature, which are properties that glass fibers do not have ${ }^{1,2}$. In addition, POFs have a high elastic strain limit with low Young's modulus and are biocompatible, which makes them advantageous for fiber Bragg grating (FBG) based strain and bio-sensing applications 3-8. Some polymers, such as PMMA, are humidity sensitive and strongly absorb water ${ }^{9}$, while other polymers, for instance TOPAS and Zeonex, are insensitive to humidity ${ }^{10-12}$. Exploiting such unique and intrinsic properties of POFs, researchers in this area have developed different single parameter POFBG sensors such as strain, temperature, humidity, pressure and soon ${ }^{13-17}$. Only little work has been done in the development of multi-parameter POFBG sensors. For instance, Zhang,C. et al developed simultaneous measurement of temperature and humidity using cascaded silica and PMMA FBGs ${ }^{18}$. Despite this sensor system provided a well-conditioned response, there was a potential problem of limited mechanical stability due to the fact that the silica and PMMA fibers were glued together. In addition, the glue could not withstand relatively high temperature and humidity which limited the range of operation of the sensor. Bhowmik,K. et al demonstrated a sensing configuration for simultaneous measurement of strain and temperature with enhanced intrinsic sensitivity based on a fiber Bragg grating (FBG) pair with one grating being inscribed in the etched and the other in unetched polymer fiber region ${ }^{19}$. Here we demonstrate the first simultaneous measurement of temperature and humidity using microstructured polymer optical fiber Bragg gratings. The sensing device is purely made of polymer materials.

\section{FIBER FABRICATION}

The mPOF was fabricated in-house at DTU Fotonik. The polymeric materials used for fiber fabrication are ZEONEX 480R produced by ZEON CORPORATION ${ }^{20}$ and commercial PMMA from NORDISK PLAST A/S ${ }^{21}$. First a ZEONEX 480R cane was fabricated as described in reference 12. The Zeonex cane was sleeved with a Zeonex tube which was then sleeved with a PMMA tube, forming an over cladding, and finally drawn to a fiber of an average diameter $150 \mu \mathrm{m}$. The diameter of the Zeonex portion is $100 \mu \mathrm{m}$, whereas the over cladding PMMA thickness is $25 \mu \mathrm{m}$. The core diameter of the fiber is $8 \mu \mathrm{m}$ and the hole to pitch ratio is 0.42 ensuring that the fiber is endlessly single mode ${ }^{22,23}$. A microscope image of the Zeonex-PMMA mPOF end facet is shown in Fig. 1.

*gewoy@ fotonik.dtu.dk

25th International Conference on Optical Fiber Sensors, edited by Youngjoo Chung, Wei Jin,

Byoungho Lee, John Canning, Kentaro Nakamura, Libo Yuan, Proc. of SPIE Vol. 10323

103234T - (C) 2017 SPIE · CCC code: 0277-786X/17/\$18 · doi: 10.1117/12.2265884 


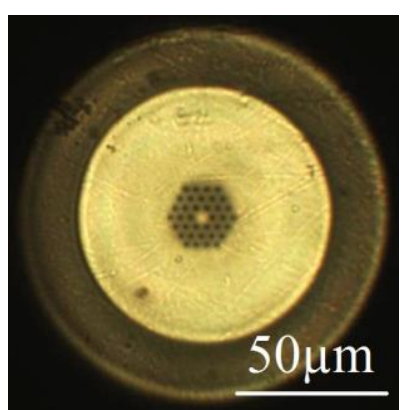

Figure 1. Optical microscope image of the fabricated Zeonex-PMMA mPOF

\section{SENSOR FABRICATION}

First, one end of a $50 \mathrm{~cm}$ long piece of the fabricated fiber was connectrorized ${ }^{24}$. From the other end, in the first five centimeters of the fiber the PMMA over cladding was etched out by using acetone, so that only Zeonex was left in this section. In the section composed only of Zeonex, four centimeters far from the end of the fiber an FBG (FBG1) was inscribed and the Bragg wavelength was at $865.62 \mathrm{~nm}$. The FBG was then annealed at $90{ }^{\circ} \mathrm{C}$ in a conventional oven for three hours and blue shifted to $847.79 \mathrm{~nm}$. After annealing two centimeters far from FBG1 a second FBG (FBG2) was inscribed in the section where PMMA was not etched out and the Bragg wavelength of this grating was at $866.11 \mathrm{~nm}$. The grating inscription technique and the configuration setup used in this work were described in reference 25 . The two FBGs then annealed together in an environmental climate chamber (CLIMACELL, MMM group) for 24 hours at $85{ }^{\circ} \mathrm{C}$ and $90 \% \mathrm{RH}$ for a stable operation of the sensor ${ }^{15}$. The new Bragg wavelengths for FBG1 and FBG2 after annealing were found to be $841.21 \mathrm{~nm}$ and $855.32 \mathrm{~nm}$, respectively.

\section{SENSOR CALIBRATION}

The calibration of the sensor was made in a climate chamber. A supercontinuum source (SuperK Compact, NKT Photonics) was used as the broadband light source and spectrometer (CCS175-Compact Spectrometer, Thorlabs) was used to continuously track and record the grating during the experiment in the climate chamber. First, relative humidity measurement was made in the range $10-90 \% \mathrm{RH}$ at $50^{\circ} \mathrm{C}$. Figure 2 (a) shows that the humidity responses of both FBG1 and $\mathrm{FBG} 2$ at $50{ }^{\circ} \mathrm{C}$. Temperature measurement was done following the $\mathrm{RH}$ measurement in the range $20-80{ }^{\circ} \mathrm{C}$ at $50 \%$ RH. Figure 2(b) shows that the temperature responses of both FBG1 and FBG2 at $50 \%$ RH.
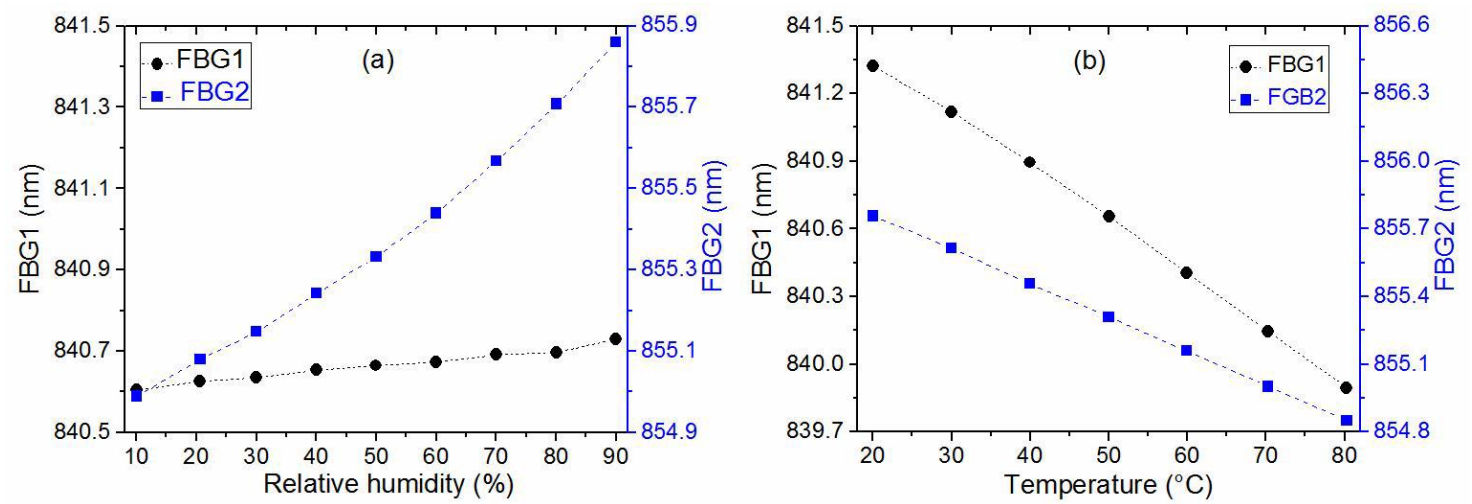

Figure 2. (a) Measured humidity response of FBG1 and FBG2 at $50{ }^{\circ} \mathrm{C}$. (b) Measured temperature response of FBG1 and FBG2 at $50 \%$ RH.

\section{ERROR ANALYSIS}

A suitable model for the responses of the two FBGs, including the nonlinear RH-response of FBG2, is

$$
\begin{aligned}
& \Delta \lambda_{1}=\alpha_{1} \Delta T+\beta_{1} \Delta H \\
& \Delta \lambda_{2}=\alpha_{2} \Delta T+\beta_{2} \Delta H+\gamma_{2} \Delta H^{2}
\end{aligned}
$$


where $\Delta \lambda_{1}$ and $\Delta \lambda_{2}$ are the net wavelength changes of FBG1 and FBG2, respectively. By combining (1) and (2) we arrive at the following expression for the change in relative humidity

where,

$$
\Delta H=\frac{-b+\sqrt{b^{2}-4 a c}}{2 a}
$$

$a=\frac{\alpha_{1}}{\alpha_{2}} \gamma_{2}, \quad b=\frac{\alpha_{1}}{\alpha_{2}} \beta_{2}-\beta_{1}, \quad c=\Delta \lambda_{1}-\frac{\alpha_{1}}{\alpha_{2}} \Delta \lambda_{2}$

Thus, once the coefficients $\alpha_{1,2}, \beta_{1,2}$ and $\gamma_{2}$ were determined by fitting polynomials to the calibration data, we were able to determine the relative humidity using (3) and subsequently the temperature from (1) by simultaneously measuring the Bragg wavelength shifts of the two FBGs. By fitting the data in Fig. 2 we found the following parameters, where $\Delta \mathrm{T}=0$ at $\mathrm{T}=50^{\circ} \mathrm{C}$ and $\Delta \mathrm{H}=0$ at $\mathrm{H}=50 \% \mathrm{RH}$ and the stated uncertainties are the standard errors of the fitting parameters.

\begin{tabular}{|l|l|l|l|}
\hline$i$ & $\alpha_{i}$ & $\beta_{i}$ & $\gamma_{i}$ \\
\hline 1 & $-23.9 \pm 0.4 \mathrm{pm} /{ }^{\circ} \mathrm{C}$ & $1.4 \pm 0.1 \mathrm{pm} / \% \mathrm{RH}$ & - \\
\hline 2 & $-15.1 \pm 0.1 \mathrm{pm} /{ }^{\circ} \mathrm{C}$ & $6.4 \pm 0.5 \mathrm{pm} / \% \mathrm{RH}$ & $0.090 \pm 0.005 \mathrm{pm} /(\% \mathrm{RH})^{2}$ \\
\hline
\end{tabular}

Using these coefficients we reconstructed the calibration points shown in the Fig.2 from the corresponding measured values of $\lambda_{1}$ and $\lambda_{2}$, see Fig.3. The root mean square deviations in the reconstructed values are $1.04 \% \mathrm{RH}$ and $0.8{ }^{\circ} \mathrm{C}$ for the relative humidity and temperature, respectively, which demonstrates that the proposed sensor system is a viable way of effectively separating the responses of temperature and relative humidity.

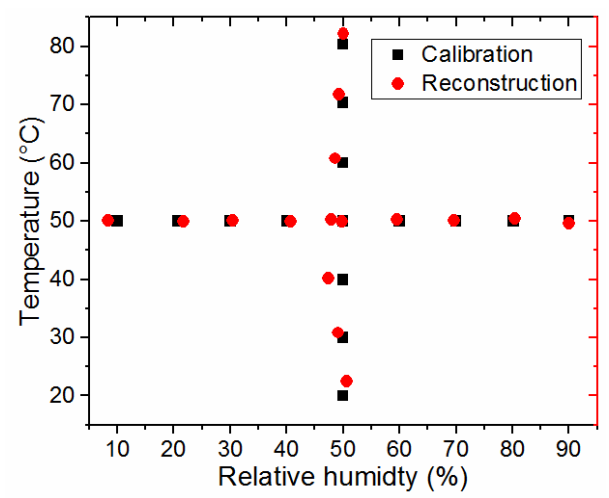

Figure 3. Reconstruction of temperature (vertical) and relative humidity (horizontal) from the measured values of $\lambda_{1}$ and $\lambda_{2}$.

\section{CONCLUSION}

In this work, we have demonstrated a sensing system for simultaneous measurement of temperature and humidity using microstructured polymer optical fiber Bragg gratings. The fiber was fabricated from two types of polymers: Zeonex, which is humidity insensitive and PMMA, which is highly humidity sensitive. An rms deviation of $1.04 \% \mathrm{RH}$ and 0.8 ${ }^{\circ} \mathrm{C}$ were observed in our experimental results. The developed sensor system offers a number of advantages such as ease of fabrication, compactness and low cost and it can be used in many applications where simultaneous measurements temperature and humidity are required.

\section{ACKNOWLEDGMENTS}

The research leading to these results has received funding from the People Programme (Marie Curie Actions) of the European Union's Seventh Framework Programme FP7/2007-2013/ under REA grant agreement $\mathrm{n}^{\circ}$ 608382. The authors also acknowledge financial support from Innovation Fund Denmark for the project BIOFORS (contract no. 138200058B) and ShapeOCT (J. No. 4107-00011A) and Danish Council for Independent Research (FTP Case No. 418400359B). 


\section{REFERENCES}

[1]. Peters,K., "Polymer optical fiber sensors - A review," Smart Mater. Struct. 20(1), 013002 (2011).

[2]. Webb,D.J., "Fiber Bragg grating sensors in polymer optical fibers," Meas. Sci. Technol. 26(9), 092004 (2015).

[3]. Dobb,H., Webb,D.J, Kalli,K., Argyros,A., Large,M.C.J., and van Eijkelenborg,M.A., "Continuous wave ultraviolet light-induced fiber Bragg gratings in few- and single-mode microstructured polymer optical fibers," Opt. Lett. 30(24), 3296-3298 (2005).

[4]. Xiong,Z., Peng,G.D., Wu,B., and Chu,P.L., "Highly tunable Bragg gratings in single-mode polymer optical fibers," IEEE Photon. Technol. Lett. 11(3), 352-354 (1999).

[5]. Stefani, A., Andresen, S., Yuan, W., Herholdt-Rasmussen,N., and Bang,O., "High sensitivity polymer optical fiber-Bragg-grating-based accelerometer," IEEE Photon. Technol. Lett. 24(9), 763-765 (2012).

[6]. Jensen,J., Hoiby,P., Emiliyanov,G., Bang,O., Pedersen,L., and Bjarklev,A., "Selective detection of antibodies in microstructured polymer optical fibers," Opt. Express 13(15), 5883-5889 (2005).

[7]. Emiliyanov,G., Jensen,J.B., Bang,O., Hoiby,P.E., Pedersen,L.H., Kjaer,E.M., and Lindvold,L., "Localized biosensing with Topas microstructured polymer optical fiber," Opt. Lett. 32(5), 460-462 (2007).

[8]. Markos,C., Yuan,W., Vlachos,K., Town,G.E., and Bang,O., "Label-free biosensing with high sensitivity in dualcore microstructured polymer optical fibers," Opt. Express 19(8), 7790-7798 (2011).

[9]. Harbach,N.G., "Fiber Bragg gratings in polymer optical fibers," PhD Thesis, Lausanne, EPFL (2008).

[10]. Markos, C., Stefani, A., Nielsen, K., Rasmussen, H. K., Yuan, W., Bang, O., "High-Tg TOPAS microstructured polymer optical fiber for fiber Bragg grating strain sensing at 110 degrees.," Opt. Express 21(4), 4758-4765 (2013).

[11]. Woyessa,W., Fasano,A., Stefani,A., Markos,C., Nielsen,K., RasmussenH.K., and Bang,O., "Single mode step-index polymer optical fibre for humidity insensitive high temperature fiber Bragg grating sensors", Opt. Express 24(2), 1253-1260 (2016).

[12]. Woyessa,W., Fasano,A., Markos,C., Nielsen,K., RasmussenH.K., and Bang,O, "Zeonex microstructured polymer optical fiber Bragg grating sensors", Photonics and Fiber Technology 2016(ACOFT, BGPP, NP), 2016.

[13]. Yuan,W., Stefani,A., Bache,M., Jacobsen,T., Rose,B., Herholdt-Rasmussen,N., Nielsen,F.K., Andresen,S., B. Sørensen,O., Hansen,K.S., and Bang,O., "Improved thermal and strain performance of annealed polymer optical fiber Bragg gratings," Opt. Commun. 284(1), 176-182 (2011)

[14]. Zhang,C., Chen,X., Webb, D. J., and Peng, G. D., "Water detection in jet fuel using a polymer optical fiber Bragg grating," Proc. SPIE 7503, 750380 (2009).

[15]. Woyessa, G., Nielsen, K., Stefani, A., Markos, C.., Bang, O., "Temperature insensitive hysteresis free highly sensitive polymer optical fiber Bragg grating humidity sensor.," Opt. Express 24(2), 1206-1213 (2016).

[16]. Carroll, K. E., Zhang,C., Webb, D. J., Kalli, K., Argyros, A., and Large, M. C. J., "Thermal response of Bragg gratings in PMMA microstructured optical fibers," Opt. Express, vol.15, no.14, pp. 8844-8850, 2007.

[17]. Pedersen, J. K. M., Woyessa, G., Nielsen, K.., Bang, O., "Intrinsic Pressure Response of a Single-Mode Cyclo Olefin Polymer Microstructured Optical Fibre Bragg Grating," Proc. 25th Int. Conf. Plast. Opt. Fibers (2016).

[18]. Zhang, C., Zhang, W., Webb, D. J., and Peng, G. D., "Optical fiber temperature and humidity sensor," Electron. Lett. 46(9), 643-644 (2010).

[19]. Bhowmik, K., Peng, G.D., Ambikairajah, E., Lovric, V., Walsh, W., Prusty, B., and Rajan, G. "Intrinsic highsensitivity sensors based on etched single-mode polymer optical fibers", Photonics Technology Letters IEEE, 27( 6), 604-607 (2015).

[20]. http://www.zeonex.com/optics.aspx

[21]. http://www.nordiskplast.dk

[22]. Kuhlmey,B., McPhedran, R. C., and de Sterke, C. M., "Modal cutoff in microstructured optical fibers," Opt. Lett. 27(19),1684-1686(2002).

[23]. Birks, T. A., Knight, J. C., and Russell, P. S., "Endlessly single-mode photonic crystal fiber," Opt. Lett. 22(13), 961-963 (1997).

[24]. Abang.A, and Webb, D. J., "Demountable connection for polymer optical fiber grating sensors," Opt. Eng. 51(8), 080503-1 (2012).

[25]. Bundalo, I.L., Nielsen,N., Markos,C., and Bang,O., "Bragg grating writing in PMMA microstructured polymer optical fibers in less than 7 minutes," Opt. Express 22(5), 5270-5276 (2014). 